\title{
Changes in oesophageal wall biomechanics after portal vein banding and variceal sclerotherapy measured by a new technique. An experimental study in rabbits
}

\author{
H GREGERSEN, L S JENSEN, AND J C DJURHUUS \\ From the Institute of Experimental Clinical Research, University of Aarhus, Aarhus, Denmark
}

SUMmary The biomechanical properties of the oesophageal wall were investigated in a rabbit model using a four electrode impedance technique. A specially designed probe with the electrodes inside a low pressure expandable insulating latex balloon was introduced in the oesophagus. Stepwise inflation and deflation was done for analysis of oesophageal compliance and hysteresis. The rabbits were allocated to three groups: a control group, one with oesophageal varices and one with varices which were treated by sclerotherapy. The oesophageal varices were induced by portal banding five months before the investigation. A uniform pattern of changes in the biomechanical properties of the oesophageal wall was seen in the group with oesophageal varices when compared with controls. The compliance was significantly decreased, and the hysteresis was lessened. Endoscopic sclerotherapy changed the wall properties to a pattern not distinguishable from normal. Thus, in vivo investigation of the biomechanical wall properties showed a significant loss of distensibility of the oesophagus with varices and restorement of the wall distensibility when the varices were treated with endoscopic sclerotherapy.

Endoscopic sclerotherapy of oesophageal varices results in oesophageal motility disorders, ' ' similar to the changes in motility pattern seen in scleroderma. ${ }^{2}$ Furthermore, it is frequently complicated by secondary strictures and dysphagia. ${ }^{34}$ In radiological studies the late findings after endoscopic sclerotherapy are strictures, mural defects, and dysmotility. ${ }^{5}$

From a previous experimental study in rabbits ${ }^{h}$ we reported that one single session of paravariceal sclerotherapy of oesophageal varices induces fibrotic changes in the middle and distal parts of the oesophageal wall. This finding might be related to changes in motility.

Little is known, however, of the motility in the oesophagus with untreated varices. Determination of mechanical wall parameters in vivo may enhance our understanding of passive (elastic) and active (con-

Address for correspondence: Dr Hans Gregersen, Institute of Experimental Clinical Research, T-Huset, Aarhus Kommunehospital, 8000 Aarhus C, Denmark.

Received for publication 21 June 1988. tractile) wall properties in the oesophagus with untreated varices as well as treated.

Valuable parameters to describe mechanical wall properties are compliance, stress relaxation, and hysteresis.? Until now in vivo determination of compliance has been impossible because of lack of an applicable method. ${ }^{8}$ By modification of a method used by Colstrup et al ${ }^{911}$ and Lose" in studies of the female urethra, it is possible to investigate the mechanical wall properties of luminal organs in vivo. A special probe was developed for simultaneous measurement of intra-oesophageal pressure and cross-sectional area (CA). From these two variables the above mentioned parameters can be calculated.

The aim was to assess the longterm influence of both oesophageal varices and sclerotherapy of the varices on the mechanical wall properties. A study was designed to examine the compliance and hysteresis after four months with persistent varices, as well as four months after a single session of endoscopic sclerotherapy. The study was carried out in a previously documented rabbit model with persistent oesophageal varices. ${ }^{12}$ 


\section{Methods}

ANIMALS

Twenty one rabbits, eight months of age, with a mean weight (SEM) of $4 \cdot 0(0 \cdot 1) \mathrm{kg}$ were randomised to the creation of oesophageal varices $(n=15)$ or a sham operation (group $1, n=6$ ). The oesophageal varices were created as previously described by prehepatic banding of the portal vein. ${ }^{12}$ In sham operated controls a midline laparotomy without banding or mobilisation of the portal vein was carried out.

Four weeks after the operation, oesophagoscopy was carried out in all animals with a fibre endoscope (Olympus GIF-P $_{1}$ ) with the animals intubated and ventilated in a respirator. The presence and size of oesophageal varices were documented by photography. The total length of the oesophagus was measured with the scope, beginning from the teeth to the gastric cardia. The animals with oesophageal varices were randomised to no treatment (group 2, $n=7$ ) or endoscopic sclerotherapy (group $3, n=8$ ) of the varices.

Endoscopic sclerotherapy was done via the fibre endoscope using $3 \mathrm{~mm}$ needle (NM-3K, Olympus). Aethoxysclerol (Polidocanol, Kreussler) was placed as four paravariceal depots of $0.5 \mathrm{ml}$ along the variceal columns with the centre of injection $2 \mathrm{~cm}$ above the gastric cardia. All these procedures were done by the same person (L S Jensen).

Five months after the operation (four months after the first endoscopy and sclerotherapy (only group 3)) all the animals were re-endoscoped followed by a mechanical investigation of the oesophagus. The mechanical investigations were carried out by another of the authors (H Gregersen), who was not aware of the randomisation and treatment of the animals. The code was broken when all the investigations were finished.

MECHANICAL WALL PROPERTIES

A specially designed four electrode impedance measuring system located inside a balloon on a $14 \mathrm{~F}$ catheter was used (Fig. 1). The inner detecting pair of electrodes had an interelectrode distance of $3 \mathrm{~mm}$ and were connected to an impedance measuring system. The outer excitation electrodes were placed

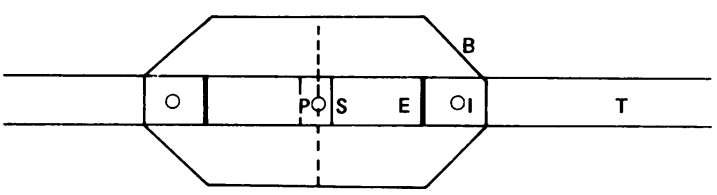

Fig. 1 Probe for measurement of pressure and crosssectional area. $B=$ balloon, $E=$ excitation electrode, $I=$ infusion channel, $P=$ pressure measuring channel, $S=$ detecting electrode, and $T=$ catheter.
$1 \mathrm{~cm}$ from each side of the detecting electrodes and connected to a generator which delivered a constant alternating current of 30 microamperes at $5 \mathrm{kHz}$. All electrodes were made of copper and wired around the catheter in $0.5 \mathrm{~mm}$ wide hollows, thus being on the same level as the surface of the catheter. The balloon, $3.5 \mathrm{~cm}$ long and cylindrical, was made of thin non-conducting latex and could be inflated through an infusion channel to a diameter of $1.5 \mathrm{~cm}(=\mathrm{a} \mathrm{CA}$ of $1.76 \mathrm{~cm}$ ) without stretching the balloon. The size of the balloon was chosen with respect to the CA measuring system.

The pressure was measured by a low compliance perfusion system connected to an external transducer (Siemens Elema strain gauge 746). The side hole was
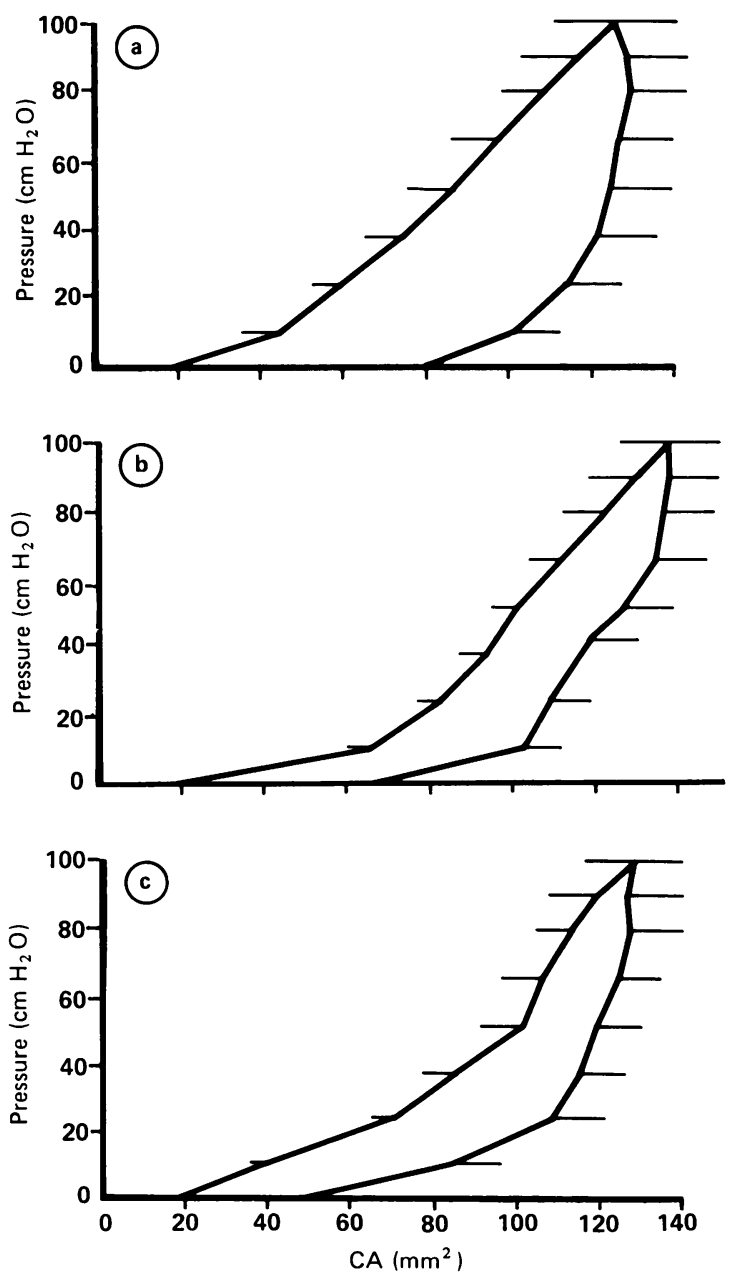

Fig. 2 Relationship between the pressure in the balloon and the resulting cross-sectional area (CA) as mean (SEM), 2 (a), $5(b)$, and 8 (c) $\mathrm{cm}$ from the cardia in the normal rabbit oesophagus. 
located inside the balloon between the detecting electrodes.

The CA (calculated as $3 \cdot 14 \times$ the square radius of the balloon between the detecting pair of electrodes) was estimated from measurement of the impedance of the fluid inside the balloon according to the field gradient principle. ${ }^{13}$ When a current $I$ is induced in a uniform cylinder by the excitation pair of electrodes, the voltage difference $\mathrm{V}$ between the detecting pair of electrodes is $V=I \times R$ (Ohm's Law). $R$, which is the electrical impedance of the fluid, can also be expressed as $\mathrm{d} \times @^{-1} \times \mathrm{CA}^{-1}$, where $\mathrm{d}$ is the distance between the detecting pair of electrodes and @ the conductivity of the fluid. Thus, the voltage difference can be expressed as $\mathrm{V}=\mathrm{I} \times \mathrm{d} \times @^{-1} \times \mathrm{CA}^{-1}$. When $\mathrm{I}$, $\mathrm{d}$, and @ are constants, it follows that $\mathrm{V}$ is inversely proportional to the CA. To obtain direct proportionality, a reciprocating unit was included in the equipment.

The upper limits for the measurements were set to a pressure of $100 \mathrm{~cm} \mathrm{H}_{2} \mathrm{O}$ or a balloon diameter of $1.5 \mathrm{~cm}$ corresponding to a $\mathrm{CA}$ of $1.76 \mathrm{~cm}$. The lower limits were a pressure of zero $\mathrm{cm}_{2} \mathrm{O}$ or a CA of $0.17 \mathrm{~cm}$ corresponding to the $\mathrm{CA}$ of the catheter.

\section{IN VIVO INVESTIGATIONS}

The procedures were carried out with the animals in a light anaesthesia with Halothane $1 \%$ and $\mathrm{N}_{2} \mathrm{O} / \mathrm{O}_{2}$ on spontaneous respiration. It was carried out as a step test in the oesophagus 2,5 , and $8 \mathrm{~cm}$ from cardia. The pressure was changed through the infusion channels in steps to $0,10,24,38,52,66,80,90$, and $100 \mathrm{~cm}$ $\mathrm{H}_{2} \mathrm{O}$ and back again using the same steps with 30 seconds between each step. Isotonic saline was infused in the balloon at a temperature of $37^{\circ} \mathrm{C}$.

All registrations of the pressure and $\mathrm{CA}$ were amplified and taped on a TEAC 501 recorder. Recordings were made by a multichannel ink jet recorder (Siemens Mingograph 805).

\section{ANALYSIS OF DATA}

The resultant midexpiratory CA was estimated 30 seconds after each pressure step with later calculations of the compliance and hysteresis. The compliance was defined as the change in CA divided by the change in pressure $(\mathrm{dCA} / \mathrm{dP})$. The hysteresis was defined as the difference in CA between deflation and inflation at a given pressure $\left(\mathrm{CA}_{\operatorname{def}(\mathrm{P})}-\mathrm{CA} \mathrm{A}_{\mathrm{inf}(\mathrm{P})}\right)$.

\section{STATISTICAL ANALYSIS}

Results are expressed as mean and (SEM). Student's $t$ test for unpaired data was used for possible differences of the compliance at the maximal induced pressure between the three groups at the same recording points. The paired $t$ test was used to show whether there were any differences in compliance between the three recording points. Results were considered significant at $\mathrm{p}<0 \cdot 05$.

\section{Results}

All the portal vein banded animals developed two trunks of tortuous oesophageal varices four weeks after the operation. These were located in the distal $5-7 \mathrm{~cm}$ of the oesophagus and bulged $2-3 \mathrm{~cm}$ into the oesophageal lumen. The sham operated animals had no varices. At the second endoscopy the varices were unchanged in the non-treated portal banded animals. The varices had completely shrunk in the animals treated by endoscopic sclerotherapy. The animals thrived well, and after five months the weight was $4 \cdot 2$ $(0 \cdot 1) \mathrm{kg}$ with no difference between the groups. None of the animals had gastrointestinal bleeding, and the mortality was zero.

The length of the oesophagus ranged between 19 and $22 \mathrm{~cm}$. Introduction of the probe and pressure stimulation resulted in a consistent pattern. After the stepwise pressure increase, the CA increased steeply in the beginning then more slowly. Stable values were not always obtained. Pressure variations caused by respiration were detected only at low induced pressures in the balloon.

The relationship between pressure and cross sectional area is shown in Figures 2, 3, and 4.

All the control animals had a non-linear relationship between pressure and $\mathrm{CA}$ with a high compliance until a pressure of $50-70 \mathrm{~cm} \mathrm{H}_{2} \mathrm{O}$. Thereafter, the relationship tended towards linearity. Only marginal insignificant differences were found between the different measuring levels $(2,5$, and $8 \mathrm{~cm}$ above the cardia). All animals showed a pronounced hysteresis during the gradual pressure decrease. The hysteresis was most pronounced at the measuring point close to cardia (Figs $2 a, b$, and c).

The relationship between the pressure and CA in the group with non-treated oesophageal varices (Figs $3 a, b$, and $c$ ) showed a uniform change in comparison

Table Compliance in oesophagus at three locations

\begin{tabular}{llll}
\hline $\begin{array}{l}\text { Distance from } \\
\text { cardia }(\mathrm{cm})\end{array}$ & Group 1 & Group 2 & Group 3 \\
\hline 2 & $126 \cdot 0(15 \cdot 9)$ & $95 \cdot 0(7 \cdot 2)$ & $119 \cdot 0(8 \cdot 8)$ \\
5 & $138 \cdot 1(17 \cdot 1)$ & $98 \cdot 5(6 \cdot 8)$ & $124 \cdot 9(11 \cdot 9)$ \\
8 & $128 \cdot 2(12 \cdot 6)$ & $90 \cdot 1(5 \cdot 0)$ & $120 \cdot 1(11 \cdot 3)$ \\
& NS & NS & NS \\
\hline
\end{tabular}

Group 1, sham operated controls; group 2, non-treated oesophageal varices; group 3, sclerotherapy of oesophageal varices. Results are expressed as mean (SEM). NS, no significance between levels. Group $1 v 2: \mathrm{p}>0.05$ at all three measuring points. Group $1 v 3$ : $p>0.3$ at all three measuring points. Group $2 v 3: p<0.05$ at all three measuring points. 

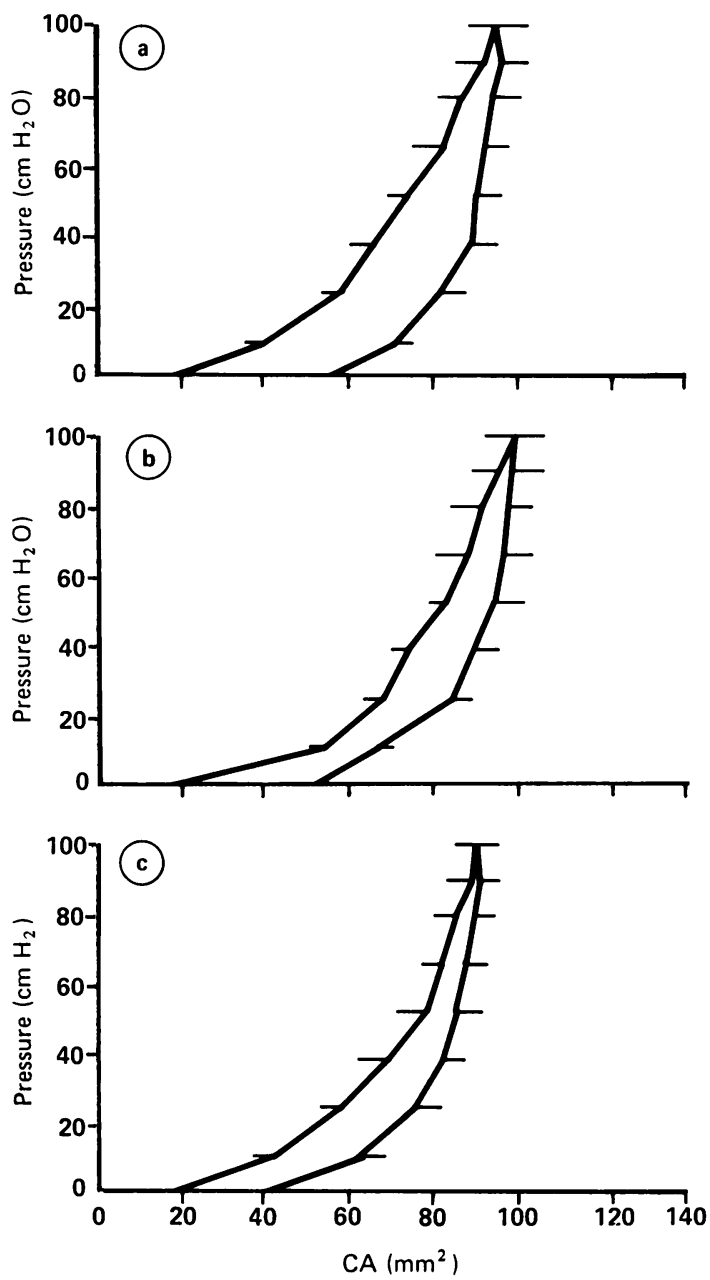

Fig. 3 Relationship between the pressure and crosssectional area $(C A)$ in the oesophagus with varices five months after portal vein banding, $2(a), 5(b)$, and $8(\mathrm{c}) \mathrm{cm}$ above the cardia.

with the controls. The compliance was significantly decreased although the non-linear pattern was essentially the same. The hysteresis decreased significantly at all three levels. No differences were observed between the levels.

The oesophagus with treated varices (group 3, Figs $4 a, b, c)$ showed a completely different pattern from that of the non-treated variceal oesophagus. The compliance was significantly larger at all levels and the hysteresis was just as pronounced as in the control cases.

The Table depicts the statistical analysis of the compliance in the oesophagus of the different
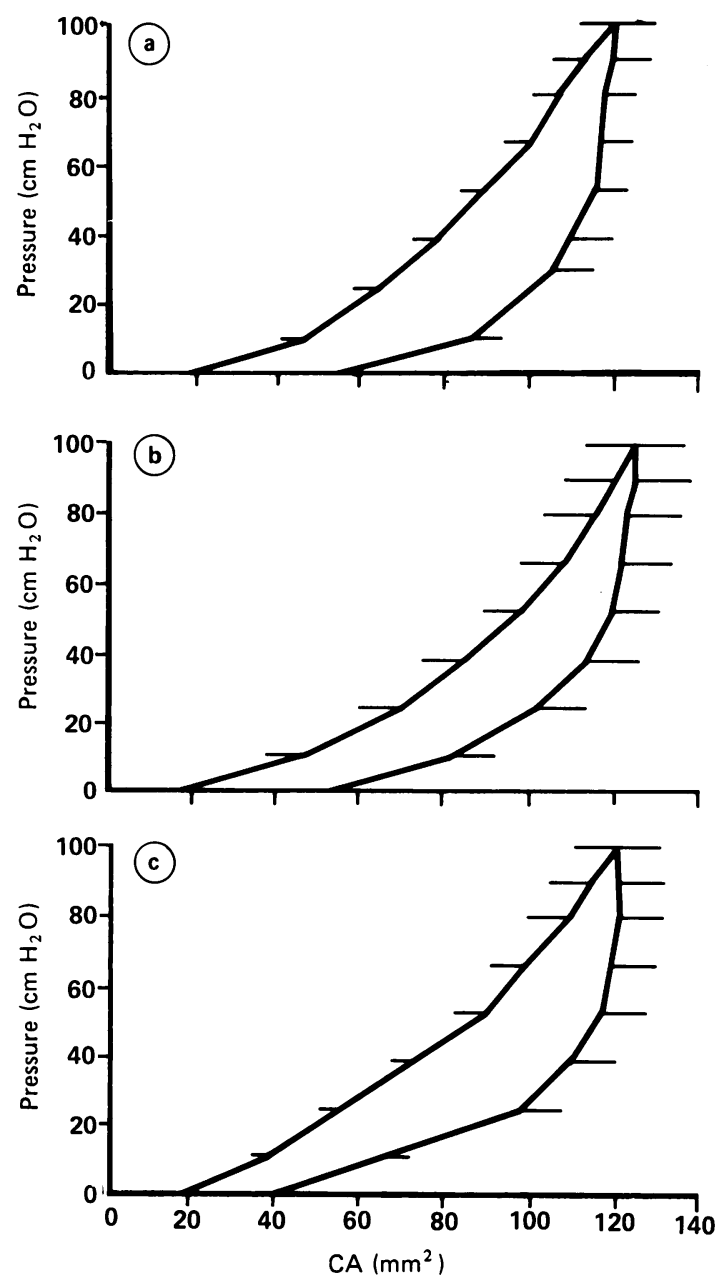

Fig. 4 Relationship between the pressure and crosssectional area $(C A)$ in the oesophagus four months after treatment of varices with endoscopic sclerotherapy, $2(a)$, $5(\mathrm{~b})$, and 8 (c) $\mathrm{cm}$ above the cardia.

groups. The group with untreated varices showed significant change in compliance from normal at all three levels.

The treated group showed no significant difference at any level from the control group. The non-treated oesophagus showed significantly lower compliance at all three levels when compared with the treated group. There was no significant difference between the different levels in the different groups. Thus, the oesophagus appeared to be rather uniform in the relationship between pressure and CA in both controls, in non-treated oesophageal varices and in the treated group. 


\section{Discussion}

Parameters derived from pressure and $\mathrm{CA}$ give important information about the tissue elasticity which previously has been very difficult to estimatè accurately in vivo. Measurements of the mechanical wall properties are becoming very important in studies of arteries, ${ }^{74}$ the bladder, ${ }^{15}$ the rectum,,${ }^{16}$ and the caecum. ${ }^{17}$ Both these regions and the oesophagus are subjected to dimensional changes. The mechanical wall properties are important factors in determining the resting pressure and the elasticity of the tissue. ' In oesophagus this is of special importance in relation to several diseases (stricture, mural defects, varices) and to longterm side effects from treatments such as dysphagia induced by endoscopic sclerotherapy. ${ }^{34}$

In the present study we decided to use a step test with pressure as an independent variable. This test allowed us, in theory, to estimate parameters related to viscoelastic properties of the tissue - that is, the compliance and the hysteresis. Using this technique it is important to consider possible sources of errors such as the slope of the wall, the temperature of the fluid and the position of the probe in the balloon. These are well described by Lose et al, " and are taken into account in the present investigation.

From the data obtained it appears that the distal third of the rabbit oesophagus seems to have rather uniform properties which are highly distensible at low pressure up to CA's of 60 to $80 \mathrm{~mm}^{2}$. This is most likely because of the biomechanical properties of the oesophageal smooth muscles. A second phase determined by overdistension of the muscles is reflecting the biomechanical properties of the connective tissue. A significant hysteresis was present at all levels signifying a highly viscoelastic oesophageal wall.

The main finding in this study was the marked decrease in viscoelastic properties of the oesophageal wall in animals with untreated oesophageal varices. Treatment of the varices by endoscopic sclerotherapy seemed to normalise all parameters. What determines the mechanical wall properties in the oesophagus is yet unknown. The quality and quantity of passive elements, however, such as collagen and elastin might be important.

The varices in this model are located in the distal third of the oesophagus. The investigations were in all groups carried out at three different zones in this particular region. The results did not differ, however, between the recording sites within each group, and therefore seems consistent at that part of the oesophagus.

The histomorphologic changes that developed in the wall of the rabbit oesophagus up to one month after endoscopic sclerotherapy using intravariceal and paravariceal injection have been well described. ${ }^{18}$ Briefly, sclerotherapy, regardless of the technique used, causes an early necrotising unspecific inflammation of the oesophageal wall followed by repair and scar formation. The vascular thrombosis occurring in the intravariceally injected animals recanalises giving rise to a complete vascular repair. In contrast a striking loss of varices was seen in the paravariceally injected animals with the remaining veins surrounded by a dense connective tissue. ${ }^{\text {Ix }}$ Paravariceal sclerotherapy also induced an increased collagen formation together with an increased breaking strength in the oesophageal wall." Surprisingly, the mere presence of oesophageal varices tends to induce collagen formation in the middle and distal third of the oesophageal wall resulting in a slightly increased mechanical strength. ${ }^{\circ}$

From the present study it is impossible to state what determines the mechanical wall properties of the oesophagus. The findings of a marked decrease in distensibility and hysteresis of the oesophageal wall with untreated varices in relation to the normal oesophageal wall may be a result of increased collagen formation. This could be induced by the vascular proliferation in the portal hypertensive animals.

Unpredictably, the fibrotic changes previously shown to be induced in the oesophageal wall one month after sclerotherapy ${ }^{\circ}$ are not accompanied by a decrease in the compliance and hysteresis four months after sclerotherapy. The most likely explanation for these findings is a nearly complete reversibility of the fibrotic changes primarily induced by the sclerotherapy. Furthermore, this will be consistent with the theory that the varices induce a tissue reaction making the oesophageal wall more rigid, and that the tissue reaction reverses when the varices are obliterated by sclerotherapy. Analogously Söderlund et af found partly reversible changes in oesophageal motility after sclerotherapy.

The new method presented here in an experimental model has to be evaluated in future clinical studies especially with respect to investigation of the mechanical wall properties before and after sclerotherapy. The results obtained by using the method have to be related to the occurrence of dysphagia and other subjective symptoms in patients with oesophageal diseases. Furthermore, the results have to be related to different tissue components of the oesophageal wall.

\section{References}

1 Sauerbruch T, Wirsching R, Leisner B, Weinzierl M, Pfahler M. Baumgartner G. Esophageal function after 
sclerotherapy of bleeding varices. Scand J Gastroenterol 1982; 17: 745-51.

2 Söderlund C, Thor K, Wiechel K-L. Oesophageal motility after sclerotherapy for bleeding varices. Acta Chir Scand 1985; 151: 249-53.

3 Sørensen TAI, Burcharth F, Pedersen ML, Lindahl F. Oesophageal stricture and dysphagia after endoscopic sclerotherapy for bleeding varices. Gut $1984 ; 25$ : 473-7.

4 Haynes WC, Sanowski RA, Foutch PG, Bellapravalu S. Esophageal strictures following endoscopic variceal sclerotherapy: clinical course and response to dilatation therapy. Gastrointest Endosc 1986; 32: 202-5.

5 Agha FP. The esophagus after endoscopic injection sclerotherapy: Acute and chronic changes. Radiology 1984; 153: 37-42.

6 Jensen LS, Laurberg S, Juhl CO, Andreassen TT. Esophageal collagen content and mechanical strength after endoscopic sclerotherapy of esophageal varices. An experimental study in rabbits. Scand J Gastroenterol 1987; 22: 743-9.

7 Dobrin PB. Mechanical properties of arteries. Physiol Rev 1978; 58: 397-460.

8 Regnier CH. Direct static measurement of obstruction. Neurourol Urodyn 1986; 5: 251-7.

9 Colstrup H, Mortensen SO, Kristensen JK. A probe for measurements of related values of cross-sectional area and pressure in the resting female urethra. Urol Res 1983; 11: 139-41.
10 Colstrup H. Rigidity of resting female urethra. Part 1. Static measurements. J Urol 1984; 132: 78-81.

11 Lose G, Colstrup H, Saksager K, Kristensen JK. New probe for measurement of related values of crosssectional area and pressure in a biological tube. Med Biol Eng Comput 1986; 24: 488-92.

12 Jensen LS, Dybdahl H, Juhl CO. Experimental prehepatic portal hypertension and esophageal varices in the rabbit. Scand J Gastroenterol 1986; 21: 225-30.

13 Harris JH, Therkelsen EE, Zinner NR. Electrical measurement of urethral flow. In: Urodynamics. London: Academic Press, 1971: 465-72.

14 Bagshaw RV, Attinger FML. Two directional delayed compliance in the canine abdominal aorta. Experimentia 1972; 28: 803-4.

15 Coolsaet B. Bladder compliance and detrusor activity during the collection phase. Neurourol Urodyn 1985; 4: 263-73.

16 Arhan P, Faverdin C, Persoz B, et al. Relationship between viscoelastic properties of the rectum and anal pressure in man. J Appl Physiol 1976; 41: 677-82.

17 Gordon AR, Siegman MJ. Mechanical properties of smooth muscle. 1. Length-tension and force-velocity relations. Am J Physiol 1971; 221: 1243-9.

18 Jensen LS, Dybdahl H, Juhl C, Nielsen TH. Endoscopic sclerotherapy of esophageal varices in an experimental animal model. A histomorphologic study. Scand $J$ Gastroenterol 1986; 21: 725-32. 